Pacific Journal of Mathematics

A NOTE ON THE ATIYAH-BOTT FIXED POINT FORMULA AND ROBERT JULES SinNer 


\title{
A NOTE ON THE ATIYAH-BOTT FIXED POINT FORMULA
}

\author{
L. M. Sibner and R. J. Sibner
}

Let $f$ be a holomorphic self map of a compact complex analytic manifold $X$. The differential of $f$ commutes with $\bar{\partial}$ and, hence, induces an endomorphism of the $\bar{\partial}$-complex of $X$. If $f$ has isolated simple fixed points, the Lefschetz formula of Atiyah-Bott expresses the Lefschetz number of this endomorphism in terms of local data involving only the map $f$ near the fixed points. For example, if $X$ is a curve, this Lefschetz number is the sum of the residues of $(z-f(z))^{-1}$ at the fixed points.

Using a well-known technique of Atiyah-Bott for computing trace formulas, we shall, in this note, give a direct analytic derivation of the Lefschetz number as a residue formula. The formula is valid for holomorphic maps having isolated, but not necessarily simple fixed points.

1. Let $E$ be the $\bar{\partial}$-complex of a compact complex analytic manifold $X$ of dimension $n$.

$$
E: 0 \longrightarrow \Gamma\left(\Lambda^{0,0}\right) \stackrel{\bar{\partial}}{\longrightarrow} \Gamma\left(\Lambda^{0,1}\right) \longrightarrow \cdots \stackrel{\partial}{\longrightarrow} \Gamma\left(\Lambda^{0, n}\right) \longrightarrow 0 \text {. }
$$

Since $E$ is elliptic, $H^{i}(X)=\operatorname{ker} \bar{\partial}_{i} / i m \bar{\partial}_{i-1}$ is finite dimensional. Denote by $T=\left\{T_{i}\right\}$ the endomorphism induced on $E$ by the holomorphic map $f$, and by $H^{j} T$ the resulting endomorphism on $H^{i}(X)$.

The Lefschetz number of $f$ is then defined by

$$
L(f)=\sum_{i=0}^{n}(-1)^{i} \operatorname{tr} H^{i} T
$$

and the finite dimensionality of the spaces $H^{i}(X)$ insures that this number is finite.

The Atiyah-Bott method of computing trace formulas reduces the problem of calculating $L(f)$ to that of finding a good parametrix for the $\bar{\partial}$-operator. In fact, let us suppose we can find operators $P_{i}: \Gamma\left(\Lambda^{0, i}\right) \rightarrow \Gamma\left(\Lambda^{0, i-1}\right), i=1, \cdots, n$, having the property that

$$
P_{i+1} \bar{\partial}_{i}+\bar{\partial}_{i-1} P_{i}=I-S_{i}
$$

where $S_{i}: \Gamma\left(\Lambda^{0, i}\right) \rightarrow \Gamma\left(\Lambda^{0, i}\right)$ are integral operators with sufficiently smooth kernels. Observe that if $\omega \in \Gamma\left(\Lambda^{0, i}\right)$ is in the kernel of $\bar{\partial}_{i}$, then the left-hand side of (1) is a co-boundary. Hence, $H^{i} I-H^{i} S$ is the zero-endomorphism on homology. Similarly, since $T$ commutes 
with $\bar{\partial}$

$$
T_{i}\left(P_{i+1} \bar{\partial}_{i}+\bar{\partial}_{i-1} P_{i}\right)=T_{i} P_{i+1} \bar{\partial}_{i}+\bar{\partial}_{i-1} T_{i-1} P_{\imath}=T_{i}-T_{i} S_{\imath}
$$

so that $H^{i} T=H^{i} T S$. Therefore,

$$
L(f)=\sum_{i=0}^{n}(-1)_{i} t r H^{i}(T S) .
$$

The generalized alternating sum formula of Atiyah-Bott says that the alternating sum of traces is the same on the chain level as on the homology level; that is,

$$
L(f)=\sum_{i=0}^{n}(-1)^{i} \operatorname{tr} H^{i} T S=\sum_{i=0}^{n}(-1)^{i} \operatorname{tr} T_{i} S_{i}
$$

provided the right-hand side is finite. This will be the case if the kernels of the operators $S_{i}$ are sufficiently smooth along the graph of $f$.

To carry out the above procedure and evaluate $L(f)$ we make an explicit choice of the operators $P_{i}$.

2. The most natural way to choose a parametrix on $X$ is to glue together the local fundamental solutions of the $\bar{\partial}$-operator using partitions of unity. Given any finite open covering $\left\{U_{\alpha}\right\}$ of $X$, there are, in each $U_{\alpha}$, integral operators $Q_{\alpha, 2}: \Gamma\left(\Lambda^{0, i}\left(U_{\alpha}\right)\right) \rightarrow \Gamma\left(\Lambda^{0, i-1}\left(U_{\alpha}\right)\right)$ $i=1, \cdots, n$ such that for $\omega \in C_{0}^{\infty}\left(U_{\alpha}\right)$

$$
\begin{aligned}
\bar{\partial} Q_{\alpha, i}(\omega) & =\omega-Q_{\alpha, i+1}(\bar{\partial} \omega) \\
\left(Q_{\alpha, i} \omega\right)\left(z^{\alpha}\right) & =\int_{U_{\alpha}} \omega\left(\zeta^{\alpha}\right) \wedge \Omega_{i}\left(z^{\alpha}, \zeta^{\alpha}\right)
\end{aligned}
$$

where $\Omega_{i}\left(z^{\alpha}, \zeta^{\alpha}\right) \in \Gamma\left(\Lambda^{0, i-1}\left(U_{\alpha}\right) \otimes \Lambda^{n, n-i}\left(U_{\alpha}\right)\right)$ is a $C^{\infty}$-section off the diaganal and has an absolutely integrable singularity.

Let $\Omega\left(z^{\alpha}, \zeta^{\alpha}\right)=\sum_{i=1}^{n}(-1)^{i} \Omega_{i}\left(z^{\alpha}, \zeta^{\alpha}\right)$. This is an $(n, n-1)$ form on $U_{\alpha} \times U_{\alpha}$ satisfying

$$
\bar{\partial} \Omega=0 .
$$

For a detailed study of Cauchy-Fantappié forms see Koppelman [2], Lieb [3], Øvrelid [4]. An explicit expression for $\Omega$ appears near the end of $\S 3$.

Suppose $f$ has $m$ isolated fixed points, $P_{1}, \cdots, P_{m}$. Let $U_{k}$ be a coordinate neighborhood containing $P_{k}$, chosen so that the sets $U_{k}$ are mutually disjoint. Let $N_{k}$ be a neighborhood of $P_{k}$, sufficiently small so that $f^{-1}\left(N_{k}\right) \subset U_{k}$ ( $f$ is continuous and $\left.f\left(P_{k}\right)=P_{k}\right)$. The collection $U_{1}, \cdots, U_{m}$ can be extended to a covering $\left\{U_{\alpha}\right\}$ and a partition of unity $\left\{\lambda_{\alpha}\right\}$ subordinate to this covering can be chosen such 
that (for $k=1, \cdots, m$ )

(i) $\operatorname{supp} \lambda_{k} \subset N_{k}$

(ii) $\lambda_{k}=1$ in a neighborhood of $P_{k}$.

Then supp $\lambda_{k} \circ f \subset f^{-1}\left(N_{k}\right) \subset U_{k}$ and $\lambda_{k} \circ f=1$ in some (other) neighborhood of $P_{k}$.

Now choose nonnegative functions $\sigma_{\alpha} \in C_{0}^{\infty}\left(U_{\alpha}\right)$ such that

(iii) $\sigma_{\alpha}=1$ on $\operatorname{supp} \lambda_{\alpha} \alpha \neq 1, \cdots, m$

(iv) $\sigma_{\alpha}=1$ on $\left\{\operatorname{supp} \lambda_{\alpha}\right\} \cup\left\{\operatorname{supp} \lambda_{\alpha} \circ f\right\} \alpha=1, \cdots, m$.

Define $P_{i}: \Gamma\left(\Lambda^{0, i}\right) \rightarrow \Gamma\left(\Lambda^{0, i-1}\right)$ by

$$
\begin{aligned}
& P_{i} \omega=\sum_{\alpha} \lambda_{\alpha} Q_{\alpha, i}\left(\alpha_{\alpha} \omega\right) \quad i=1, \cdots, n \\
& P_{0} \omega=0 .
\end{aligned}
$$

From (4a) we obtain

$$
\begin{array}{rlrl}
\bar{\partial} P_{i} \omega+P_{i+1} \bar{\partial} \omega & =\omega+\sum_{\alpha} \bar{\partial} \lambda_{\alpha} Q_{\alpha, i}\left(\sigma_{\alpha} \omega\right)-\sum_{\alpha} \lambda_{\alpha} Q_{\alpha, i+1}\left(\bar{\partial} \sigma_{\alpha} \wedge \omega\right) \\
& =\omega-S_{i} \omega & i=0, \cdots, n
\end{array}
$$

where

$$
\begin{aligned}
& S_{i} \omega(z)=-\sum_{\alpha} \bar{\partial} \lambda_{\alpha}(z) \int_{U_{\alpha}} \sigma_{\alpha}(\zeta) \omega(\zeta) \wedge \Omega_{i}(z, \zeta) \\
& +\sum_{\alpha} \lambda_{\alpha}(z) \int_{U_{\alpha}} \bar{\partial} \sigma_{\alpha}(\zeta) \wedge \omega(\zeta) \wedge \Omega_{i+1}(z, \zeta)
\end{aligned}
$$

(We consistently suppress the coordinate superscript when possible: writing, for example, $\sigma_{\alpha}(\zeta)$ for $\sigma_{\alpha}\left(\zeta^{\alpha}\right)$.)

3. Because of the construction of the covering and the patching functions, the kernel of $S_{i}$ is smooth in a neighborhood of the graph of $f$. In fact, if $\alpha>m$, then $f$ has no fixed points in $U_{\alpha}$ and therefore, $\zeta-f(\zeta)$ is bounded away from zero so that $\Omega_{i}(f(\zeta), \zeta)$ is a $C^{\infty}$-function in $U_{\alpha}$. Furthermore, in $U_{k}, k \leqq m$, we have chosen $\lambda_{k}$ so that $\lambda_{k}(f(\zeta)) \equiv 1$ in a neighborhood of $P_{k}$. Then, $\bar{\partial} \lambda_{k}(f(\zeta))=0$ near $\zeta=f(\zeta)$. Also, since $\sigma_{k}(\zeta) \equiv 1$ on the support of $\lambda_{k}(f(\zeta))$, we have $\bar{\partial} \sigma_{\alpha}(\zeta)=0$ near $\zeta=f(\zeta)$. Thus, the kernel of $S_{i}$ may be evaluated along the graph of $f$ to obtain:

$$
\begin{aligned}
\sum_{0}^{n}(-1)^{i} \operatorname{tr}\left(T_{i} S_{i}\right)= & \sum_{\alpha}\left\{\sum_{1}^{n}(-1)^{i+1} \int_{U_{\alpha}} \bar{\partial} \lambda_{\alpha}(f(\zeta)) \wedge \sigma_{\alpha}(\zeta) \Omega_{i}(f(\zeta), \zeta)\right\} \\
& +\sum_{\alpha}\left\{\sum_{0}^{n-1}(-1)^{i} \int_{U_{\alpha}} \lambda_{\alpha}(f(\zeta)) \bar{\partial} \sigma_{\alpha}(\zeta) \wedge \Omega_{i+1}(f(\zeta), \zeta)\right\} \\
= & -\sum_{\alpha} \int_{U_{\alpha}} \bar{\partial}\left\{\lambda_{\alpha}(f(\zeta)) \sigma_{\alpha}(\zeta)\right\} \wedge \sum_{1}^{n}(-1)^{i} \Omega_{i}\left(f\left(\zeta^{\alpha}\right), \zeta^{\alpha}\right)
\end{aligned}
$$

from which 


$$
L(f)=-\sum_{\alpha} \int_{U_{\alpha}} \bar{\partial}\left\{\lambda_{\alpha}(f(\zeta)) \sigma_{\alpha}(\zeta)\right\} \wedge \Omega(f(\zeta), \zeta) .
$$

In $U_{\alpha}$, for $\alpha>m, f$ has no fixed points. Using (4c), integrating by parts, and making use of the fact that $\sigma_{\alpha}$ has compact support in $U_{\alpha}$, we have

$$
\begin{aligned}
\int_{U_{\alpha}} \bar{\partial}\left\{\lambda_{\alpha}(f(\zeta)) \sigma_{\alpha}(\zeta)\right\} \wedge \Omega(f(\zeta), \zeta) & =\int_{U_{\alpha}} \bar{\partial}\left\{\lambda_{\alpha}(f(\zeta)) \sigma_{\alpha}(\zeta) \Omega(f(\zeta), \zeta)\right\} \\
& =\int_{\partial_{U_{\alpha}}} \lambda_{\alpha}(f(\zeta)) \sigma_{\alpha}(\zeta) \Omega(f(\zeta), \zeta) \equiv 0 .
\end{aligned}
$$

For $\alpha=k \leqq m$, let $B_{k}$ be a ball around $P_{k}$ on which $\lambda_{k}(f(\zeta)) \equiv 1$. Since $\sigma_{k}(\zeta) \equiv 1$ on the support of $\lambda_{k}(f(\zeta))$,

$$
\begin{aligned}
L(f)=-\sum_{k=1}^{m} \int_{U_{k}-B_{k}} \bar{\partial}\left\{\lambda_{k}(f(\zeta)) \Omega(f(\zeta), \zeta)\right\} & =\sum_{k=1}^{m} \int_{\partial B_{k}} \lambda_{k}(f(\zeta)) \Omega(f(\zeta), \zeta) \\
& =\sum_{k=1}^{m} \int_{\partial B_{k}} \Omega(f(\zeta), \zeta) .
\end{aligned}
$$

Using local coordinates in $B_{k}$, let $g_{i}\left(\zeta^{k}\right)=\zeta_{i}^{k}-f_{i}\left(\zeta^{k}\right), i=1, \cdots, n$. Then, for $n>1$,

$$
\left.\Omega\left(z^{k}, \zeta^{k}\right)=\frac{(n-1) !}{(2 \pi i)^{n}}\left|\zeta^{k}-z^{k}\right|^{-2 n} \sum_{i=1}^{n}(-1)^{i+1} \overline{\zeta_{i}^{k}-z_{i}^{k}} \bigwedge_{\substack{j=1 \\ j \neq i}}^{n} \overline{d \zeta_{j}^{k}}-\overline{d z_{j}^{k}}\right) \bigwedge_{l=1}^{n} d \zeta_{l}^{k}
$$

and

$$
L(f)=\frac{(n-1) !}{(2 \pi i)^{n}} \sum_{k=1}^{m} \int_{\partial B_{k}}\left(\Sigma\left|g_{i}^{k}\right|^{2}\right)^{-n} \sum_{i=1}^{n}(-1)^{i+1} \overline{g_{i}^{k}} \bigwedge_{\substack{j=1 \\ j \neq i}}^{n} \overline{d g_{j}^{k}} \bigwedge_{l=1}^{n} d \zeta_{l}^{k}
$$

which is the desired formula.

For $n=1, \Omega\left(z^{k}, \zeta^{k}\right)=(1 / 2 \pi i)\left(d \zeta^{k} / \zeta^{k}-z^{k}\right)$ and

$$
L(f)=\frac{1}{2 \pi i} \sum_{k=1}^{m} \int_{\partial B_{k}} \frac{d \zeta^{k}}{\zeta^{k}-f\left(\zeta^{k}\right)}=\sum_{f(\zeta)=\zeta} \operatorname{Res}(\zeta-f(\zeta))^{-1} .
$$

Note. Other proofs of this result have recently been given by Toledo [5] and Tong [6] using different techniques.

\section{REFERENCES}

1. M. F. Atiyah and R. Bott, A Lefschetz fixed point formula for elliptic complexes, $I$ and II, Annals of Math., 86 (1967), 374-407; 88 (1968), 451-491.

2. Walter Koppelman, The Cauchy integral for differential forms; Bull. Amer. Math. Soc., 73 (1967), 554-556.

3. Ingo Lieb, Die Cauchy-Riemannschen Differentialgleichungen auf streng pseudokonvexen Gebieten, Math. Ann., 190 (1970), 6-44.

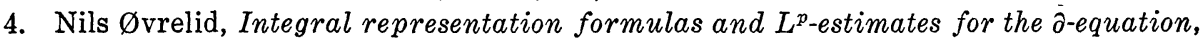
preprint. 
5. Domingo Toledo, On the Atiyah-Bott formula for isolated fixed points, J. Differential Geometry, 8 (1973), 401-436.

6. Yue Lin L. Tong, de Rham's integrals and Lefschetz fixed point formula for d" cohomology, Bull. Amer. Math. Soc., 78 (1972), 420-422.

Received May 29, 1973. The first author was supported in part by National Science Foundation grant GP-27960. The second author was supported in part by National Science Foundation grant GP-7952X3.

The Institute for AdVANCed Study

Current addresses: L. M. Sibner

Polytechnic Institute of New York

Brooklyn, NY 11201

R. J. Sibner

City University of New York

Brooklyn College

Brooklyn, NY 11210 



\section{PACIFIC JOURNAL OF MATHEMATICS}

\section{EDITORS}

RICHARD ARENS (Managing Editor)

University of California

Los Angeles, California 90024

\section{J. DUGUNDJI}

Department of Mathematics University of Southern California Los Angeles, California 90007

D. Gilbarg and J. Milgram

Stanford University

Stanford, California 94305

University of Washington
Seattle, Washington 98105

ASSOCIATE EDITORS
E. F, BECKENBACH
B. H. NEUMANN
F. WOLF
K. Yoshida

\section{SUPPORTING INSTITUTIONS}

\author{
UNIVERSITY OF BRITISH COLUMBIA \\ CALIFORNIA INSTITUTE OF TECHNOLOGY \\ UNIVERSITY OF CALIFORNIA \\ MONTANA STATE UNIVERSITY \\ UNIVERSITY OF NEVADA \\ NEW MEXICO STATE UNIVERSITY \\ OREGON STATE UNIVERSITY \\ UNIVERSITY OF OREGON \\ OSAKA UNIVERSITY
}

\author{
UNIVERSITY OF SOUTHERN CALIFORNIA \\ STANFORD UNIVERSITY \\ UNIVERSITY OF TOKYO \\ UNIVERSITY OF UTAH \\ WASHINGTON STATE UNIVERSITY \\ UNIVERSITY OF WASHINGTON \\ * * * * \\ AMERICAN MATHEMATICAL SOCIETY \\ NAVAL WEAPONS CENTER
}

The Supporting Institutions listed above contribute to the cost of publication of this Journal, but they are not owners or publishers and have no responsibility for its content or policies.

Mathematical papers intended for publication in the Pacific Journal of Mathematics should be in typed form or offset-reproduced, (not dittoed), double spaced with large margins. Underline Greek letters in red, German in green, and script in blue. The first paragraph or two must be capable of being used separately as a synopsis of the entire paper. Items of the bibliography should not be cited there unless absolutely necessary, in which case they must be identified by author and Journal, rather than by item number. Manuscripts, in duplicate if possible, may be sent to any one of the four editors. Please classify according to the scheme of Math. Rev. Index to Vol. 39. All other communications to the editors should be addressed to the managing editor, or Elaine Barth, University of California, Los Angeles, California, 90024.

100 reprints are provided free for each article, only if page charges have been substantially paid. Additional copies may be obtained at cost in multiples of 50 .

The Pacific of Journal Mathematics is issued monthly as of January 1966. Regular subscription rate: $\$ 72.00$ a year (6 Vols., 12 issues). Special rate: $\$ 36.00$ a year to individual members of supporting institutions.

Subscriptions, orders for back numbers, and changes of address should be sent to Pacific Journal of Mathematics, 103 Highland Boulevard, Berkeley, California, 94708.

PUBLISHED BY PACIFIC JOURNAL OF MATHEMATICS, A NON-PROFIT CORPORATION

Printed at Kokusai Bunken Insatsusha (International Academic Printing Co., Ltd.), 270, 3-chome Totsuka-cho, Shinjuku-ku, Tokyo 160, Japan.

Copyright (C) 1973 by Pacific Journal of Mathematics Manufactured and first issued in Japan 


\section{Pacific Journal of Mathematics}

\section{Vol. 53, No. $2 \quad$ April, 1974}

Kenneth Abernethy, On characterizing certain classses of first countable spaces by

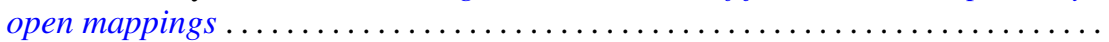

Ross A. Beaumont and Donald Lawver, Strongly semisimple abelian groups .......

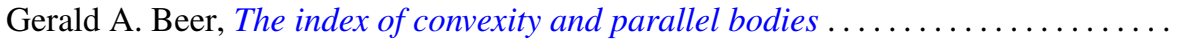

Victor P. Camillo and Kent Ralph Fuller, On Loewy length of rings ..............

Stephen LaVern Campbell, Linear operators for which $T^{*} T$ and $T T^{*}$ commute.

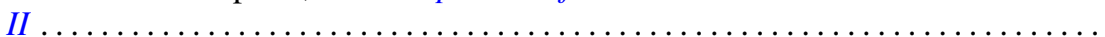

Charles Kam-Tai Chui and Philip Wesley Smith, Characterization of a function by

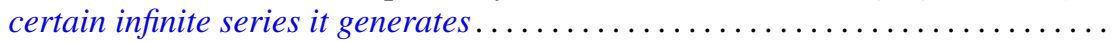

Allan L. Edelson, Conjugations on stably almost complex manifolds . ...........

Patrick John Fleury, Hollow modules and local endomorphism rings . . ..........

Jack Tilden Goodykoontz, Jr., Connectedness im kleinen and local connectedness in

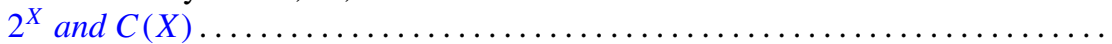

Robert Edward Jamison, II, Functional representation of algebraic intervals .......

Athanassios G. Kartsatos, Nonzero solutions to boundary value problems for

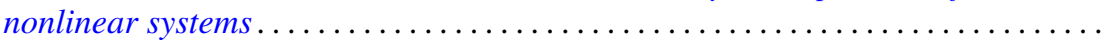

Soon-Kyu Kim, Dennis McGavran and Jingyal Pak, Torus group actions on simply

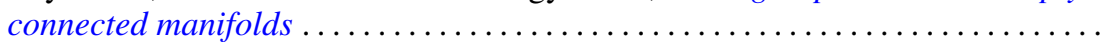

David Anthony Klarner and R. Rado, Arithmetic properties of certain recursively

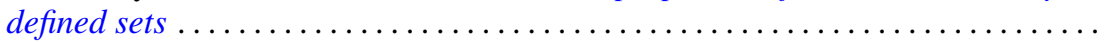

Ray Alden Kunze, On the Frobenius reciprocity theorem for square-integrable

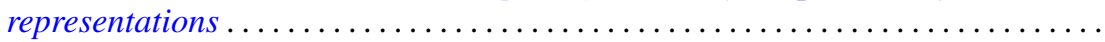

John Lagnese, Existence, uniqueness and limiting behavior of solutions of a class of differential equations in Banach space...

Teck Cheong Lim, A fixed point theorem for families on nonexpansive mappings Lewis Lum, A quasi order characterization of smooth continua

Andy R. Magid, Principal homogeneous spaces and Galois extensions . .

Charles Alan McCarthy, The norm of a certain derivation ..... . .

Louise Elizabeth Moser, On the impossibility of obtaining $S^{2} \times S^{1}$ by elementary surgery along a knot. .

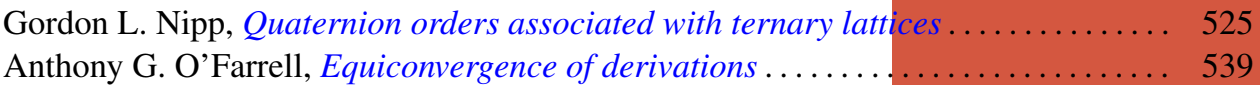

Dorte Olesen, Derivations of $A W^{*}$-algebras are inner . . . . . . . . . . . . . . . 555

Dorte Olesen and Gert Kjærgaard Pedersen, Derivations of $C^{*}$-algebras have

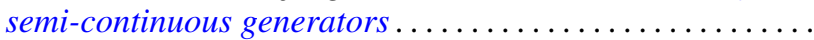

Duane O’Neill, On conjugation cobordism.

Chull Park and S. R. Paranjape, Probabilities of Wiener paths crossing differentiable

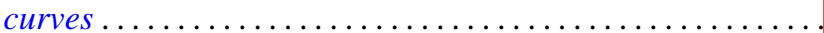

Edward Ralph Rozema, Almost Chebyshev subspaces of $L^{1}(\mu$;

Lesley Millman Sibner and Robert Jules Sibner, A note on the Atiyah-Bott fixed

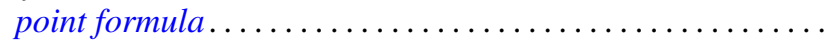

Betty Salzberg Stark, Irreducible subgroups of orthogonal groups generated by

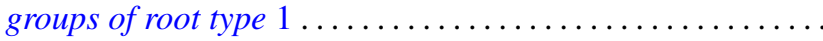

N. Stavrakas, A note on starshaped sets, $(k)$-extreme points and the half ray

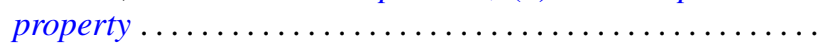

Carl E. Swenson, Direct sum subset decompositions of $Z \ldots \ldots$ 